This PDF is a selection from a published volume from the National Bureau of Economic Research

Volume Title: Social Security Programs and Retirement around the World: The Relationship to Youth Employment

Volume Author/Editor: Jonathan Gruber and David A. Wise, editors

Volume Publisher: University of Chicago Press

Volume ISBN: 978-0-226-30948-4; 0-226-30948-7

Volume URL: http://www.nber.org/books/grub08-1

Conference Date:

Publication Date: February 2010

Chapter Title: The Interaction of Youth and Elderly Labor Markets in Canada

Chapter Author: Michael Baker, Jonathan Gruber, Kevin Milligan

Chapter URL: http://www.nber.org/chapters/c8252

Chapter pages in book: (77 - 97) 


\title{
The Interaction of Youth and Elderly Labor Markets in Canada
}

\author{
Michael Baker, Jonathan Gruber, and Kevin Milligan
}

\subsection{Introduction}

The composition of the Canadian labor force has changed dramatically over the past few generations. One of the most important changes has been in the age composition. This change has been driven partially by demographics as the baby boom generation pushed its way through youth and middleage; and now approaches traditional retirement ages. However, in addition to demographic thrusts there have also been behavioral changes as Canadians react both to macroeconomic and fiscal incentives to work. Seeing these large composition changes, the potential impact of labor market trends in one age segment on other age segments becomes an important question.

On the production side of the economy, younger and older workers can in theory be either substitutes or complements. For example, if there are important gains from sharing knowledge, training, or combining experience levels to produce output, then older and younger workers may be complements. On the other hand, if there is little substantive difference between workers of different ages, then older and younger workers may be substitutes. It is important to keep in mind, however, that a large change in the supply of older workers can also have an impact on the demand for output, meaning

Michael Baker is professor of economics and public policy at the University of Toronto and a research associate of the National Bureau of Economic Research. Jonathan Gruber is professor of economics and associate head of the Department of Economics at the Massachusetts Institute of Technology and a research associate of the National Bureau of Economic Research. Kevin Milligan is associate professor of economics at the University of British Columbia and a faculty research fellow of the National Bureau of Economic Research.

This chapter was prepared as part of the NBER International Social Security project. We thank Kelvin Chan for excellent research assistance. 
that the number of jobs in the economy will change as well, not just the identity of who fills them.

In previous work, we have investigated the strength of the fiscal incentives to retire (Gruber 1999), estimated their impact on retirement decisions (Baker, Gruber, and Milligan 2004), and simulated the impact of reforms on elderly labor force behavior (Baker, Gruber, and Milligan 2007). In this chapter, we build on this existing work by examining the impact of the previously-studied long-run trends in elderly labor market behavior on younger workers.

We begin by providing a history of public pensions in Canada, viewed in the context of the political pressures coming from both older and younger workers. We then present some time series graphs of labor market behavior from the 1970s to the 2000s by age group and sex, looking for evidence of substitution between older and younger workers. Finally, we present some regression results to check how well the inferences from the graphs hold up to a more rigorous analysis.

\subsection{History of Public Pension Reforms in Canada}

The development of public pensions in Canada can be divided into five distinct eras, each with its own social concerns, policy debates, and policy actions. In this section we review each of these eras in order to provide historical context for the debate about the relationship between older and younger workers. Our historical research consisted of reviewing articles published in The Globe and Mail from 1950 to the present. We do not focus here on the parametric details of the different reforms and pensions, but instead on the politics surrounding each reform.

\subsubsection{0s/1950s: Introduction of the Old Age Security (OAS)}

Before the Second World War, the Royal Commission on DominionProvincial Relations (commonly called the Rowell-Sirois Commission) laid the groundwork for major changes to the Canadian federation in response to the economic crises of the Great Depression. Included in the recommendations of the Commission were several proposals to enhance the ability of the federal government to provide national social insurance, such as unemployment insurance and pensions, which had been provided provincially until that point. After the war, progress on some of the recommendations was made by the Liberal (centrist) government of Louis St. Laurent with the introduction of a family allowance, a national health insurance program, and public pensions. These were meant to create a "comprehensive social security program" that was "based on increasing acceptance of the principles of social justice" (Globe and Mail, October 26, 1951). The concern that generated the policy moves, therefore, was one of social justice and a desire to reduce misery and want. 
The public pension component of the post-war policy development was called the Old Age Security (OAS) pension. This pension was a universal demogrant paid to those age seventy and over and was funded on a pay-asyou-go basis from dedicated taxes. The predominant issues in the debate were the nature of funding and the base for taxation. No fewer than six editorials in the Globe and Mail between 1950 and 1953 criticized the OAS system for its lack of prefunding and the nonrelationship at an individual level between taxes paid and benefits received. Notable for its absence was any discussion of the impact of pensions on labor market behavior.

\subsubsection{0s: Introduction of the Canada Pension Plan (CPP)}

In the 1960s, continued concern about the well-being of the elderly led to pressure for an expansion of the public pension system. The Liberals, now led by Prime Minister Lester B. Pearson, argued that 70 percent of Canadians were not covered by workplace pensions and that an employment-based public pension plan could improve the incomes of the elderly. The opposition Conservatives preferred to enhance the existing OAS system with an addition of ten dollars per month. Extra-parliamentary opposition came from the insurance industry, which argued that private pensions were a prime source of investment capital that would disappear with the introduction of a public plan. There was also some debate about prefunding the pension, which was one of the primary issues leading to Quebec's decision to form its own plan so that Quebec could pursue its social investing goals. In the end, the Canada Pension Plan became law and began collecting contributions in 1966 and paying benefits in 1967 as a pay-as-you-go plan. The Quebec Pension Plan (QPP) was introduced at the same time and was in many ways similar to the CPP.

While labor market concerns were not pivotal in the discussion, one argument raised during the debates was the benefit of a portable public pension to workers, in contrast to employment-based pensions that tended to tie an employee to an employer.

\subsubsection{0s: Early Retirement in the CPP/QPP}

The next era of pension reform arrived in the early 1980s. Two social concerns led to pressure for reform. First, high unemployment - especially among the youth-led to demands that older workers be forced out of the labor force to "make room" for younger workers. There was also a desire to allow the elderly more time in retirement; more leisure and less work.

In 1984, the Parti Quebecois (social democratic) government in Quebec introduced an early retirement option to the Quebec Pension Plan that allowed for actuarially-adjusted retirement with benefits as early as age sixty. According to the Globe and Mail on December 20,1986, the intent of the change was to lower unemployment. A federal election in 1984 delayed the response of the Canada Pension Plan, but by 1987 the new Progressive 
Conservative government had implemented a similar early retirement package in the rest of the country for the CPP.

In contrast to the earlier eras, the early retirement reform in 1984 to 1987 was directly motivated by concerns emanating from the labor market. This was the stated motivation of the government and also appeared in arguments by organizations outside government.

\subsubsection{0s: Reforming the CPP}

The next era of change in public pensions in Canada focused on the Canada Pension Plan in the mid-1990s. The motivation for reform was the longterm financial health of the program. Projections from the Chief Actuary suggested that contribution rates would have to rise dramatically if promised benefits were to be paid.

Several possibilities for reform were contemplated. Higher payroll taxes were discussed both as affecting intergenerational burdens and as affecting labor markets. There was a fear that higher payroll taxes would increase unemployment. In addition, proposals to increase the retirement age were met with the charge that this would "clog up job opportunities" (Globe and Mail, June 5, 1996).

\subsubsection{0s: Labor Market Shortages}

The final era to be considered is the boom period starting in the middle part of the 2000s decade. With Canadian unemployment rates reaching generational lows, discussion shifted from unemployment to worker shortages in many industries. The policy actions under consideration were changes to public pensions to encourage more work (see Milligan 2005) and also changes to mandatory retirement regulations. Several provinces changed their labor laws to make them less amenable to mandatory retirement in union contracts. An interesting feature of this debate has been the lack of vigor among those supporting mandatory retirement. Because of labor market tightness, there has been little concern about the impact of these changes on the work opportunities of the young.

\subsubsection{Summary}

To conclude, the importance of labor market considerations in the public debate about public pensions has varied tremendously through time. In the first post-war reforms, the welfare of the elderly was of utmost concern. However, as unemployment became a dominant social issue in the early 1980s, the impact of elderly work on younger workers gained in political importance. Reforms in the 1990s that aimed to restore long-run financial stability to public pensions were evaluated in part by considering their impact on labor markets. Finally, the labor market boom of the 2000s has seemingly removed concerns about the impact of elderly work on the young from the political consciousness. 


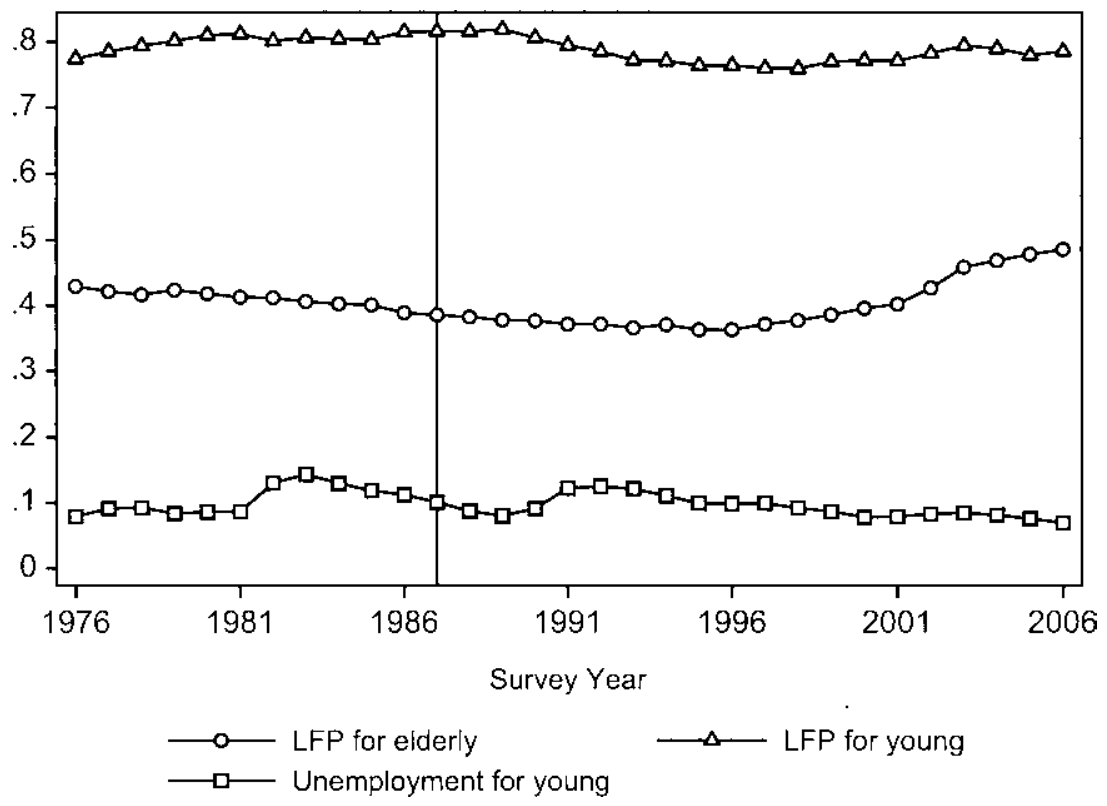

Fig. 2.1 Evolution of elderly labor force participation for elderly and the young, both sexes

Figure 2.1 shows the development of elderly labor force participation over the 1976 to 2006 time period for males and females pooled together. There is a line drawn in 1987 when the early retirement provisions of the CPP were introduced. Elderly in this graph is defined as the age range fifty-five to sixty-four. (We explain the data source in detail in the next section.) Also on the graph is the labor force participation (LFP) rate for the young and the unemployment rate for the young, where young is defined as ages twenty to twenty-four. Elderly labor force participation moves quite smoothly and slowly down from 1976 to 1996 , dropping from 42.9 percent down to 36.3 percent. After 1996, elderly LFP increases over the next ten years up to 48.5 percent. This phenomenon is studied in Schirle (2008), who finds that a substantial source of the trend is joint retirement-married males are increasingly likely to have a still-working wife, and do not want to retire alone. The unemployment rate and LFP rate for the young show more signs of cyclicality than evident for the elderly. However, in the late 1990s as elderly LFP rose, the LFP of the young appears to have risen as well, providing some preliminary evidence against a "crowd out" effect of elderly LFP on the labor market behavior of the young.

Looking at males and females separately in figures 2.2 and 2.3, subtle differences emerge. First, elderly LFP for males declines by about 15 percentage points from 1976 to 1996, before rebounding over the last decade. 


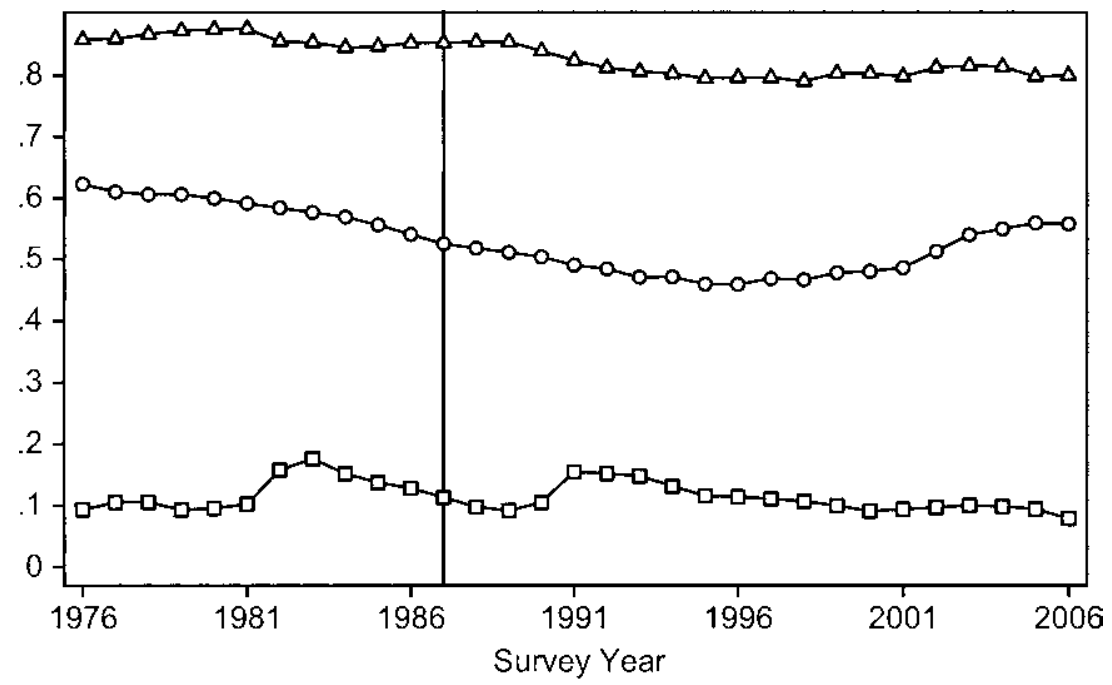

$\longrightarrow$ LFP for elderly $\quad \longrightarrow$ LFP for young

$\longrightarrow$ - Unemployment for young

Fig. 2.2 Evolution of elderly labor force participation for elderly and the young, males

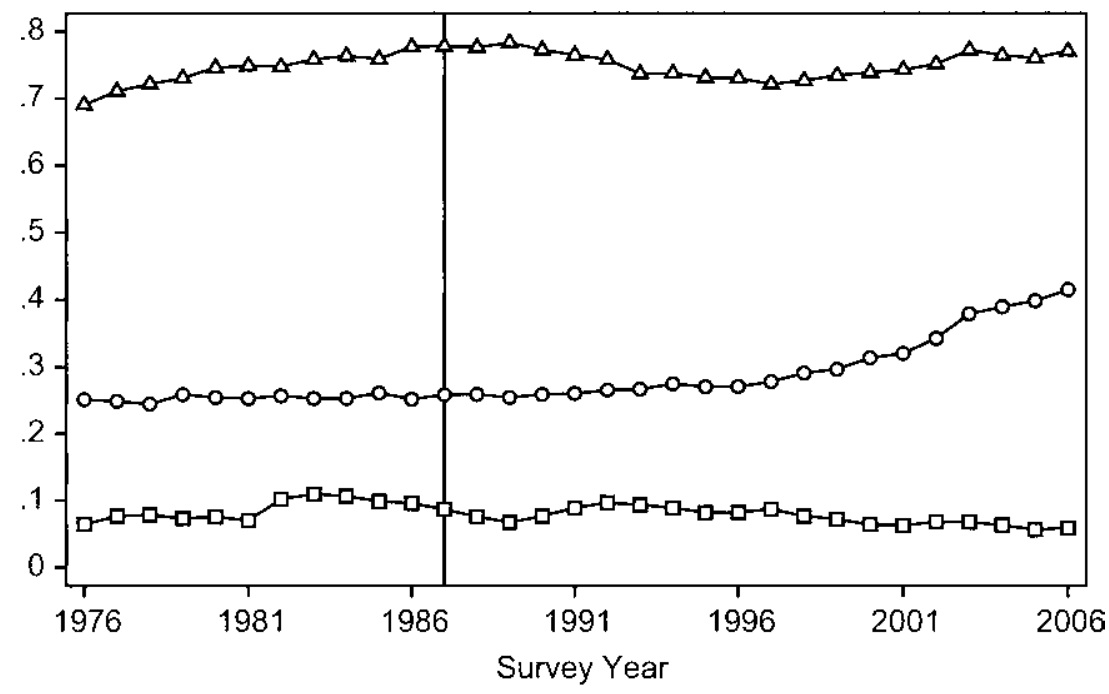

$$
\begin{aligned}
& \square-\text { LFP for elderly } \\
& \square-\Delta-\text { Unemployment for young }
\end{aligned}
$$

Fig. 2.3 Evolution of elderly labor force participation for elderly and the young, females 
In contrast, elderly female LFP grows gently until the mid-1990s, and more sharply thereafter. For the young, the lines for males show higher cyclicality. Unemployment rates (in particular for males) rise more sharply in the recessions of the early 1980s and early 1990s, whereas female unemployment changes are more muted. As with the pooled sex graphs, however, there is little evidence here that the labor supply changes of the elderly are having impact on the young.

\subsection{Time Trends}

To examine the impact of the labor market behavior of the old on the work of the young, we now turn to the data. The best data source available to us is the monthly Labor Force Survey (LFS) conducted by Statistics Canada. The Labor Force Survey is a monthly survey into which a nationally representative sample is chosen. Households stay in the survey for six months. The microdata are available from January 1976 to 2006. Sample sizes are typically about 50,000 per month. This survey gives us the best combination of long time frame, detailed and consistent questions, and large sample. Alternatives such as the Survey of Consumer Finances or the Census do not give annual coverage and are not available much earlier than the LFS.

The first step in preparing our analysis is to divide the LFS sample into age groups. We do this by designating individuals age twenty to twenty-four as "young," twenty-five to fifty-four as "prime age" and fifty-five to sixty-four as "elderly." We then form variables indicating the labor market activity of each individual, with variables for labor force participation, employment, unemployment, and in school. To form the annual time series that we use for this analysis we simply pool together the twelve months within each calendar year.

We plot both sexes pooled together, followed by separate graphs for males and females in each case. Because the substitution between older and younger workers could happen between males and females, the overall pooled graphs are most relevant for the study of elderly-young labor market interactions. However, the pooled graphs obscure some of the long-run trends affecting each sex, so we also provide separate graphs by sex.

The time series graph shown in figure 2.4 plots the labor force participation (LFP) of the elderly against unemployment rates for the young and prime age groups. The motivation for this graph is to see whether movements in elderly LFP have translated into impacts on the work opportunities of the rest of the labor market. The overwhelming impression of elderly LFP over the first twenty years of the sample is its flatness up to 1996. Over this time period, the ebbs and flows of the business cycle are evident on the unemployment rates of the young and prime age samples. Over the last ten years of the series, the LFP of the elderly increased by more than 10 percentage points. However, over this same time period, the unemployment rates of the 


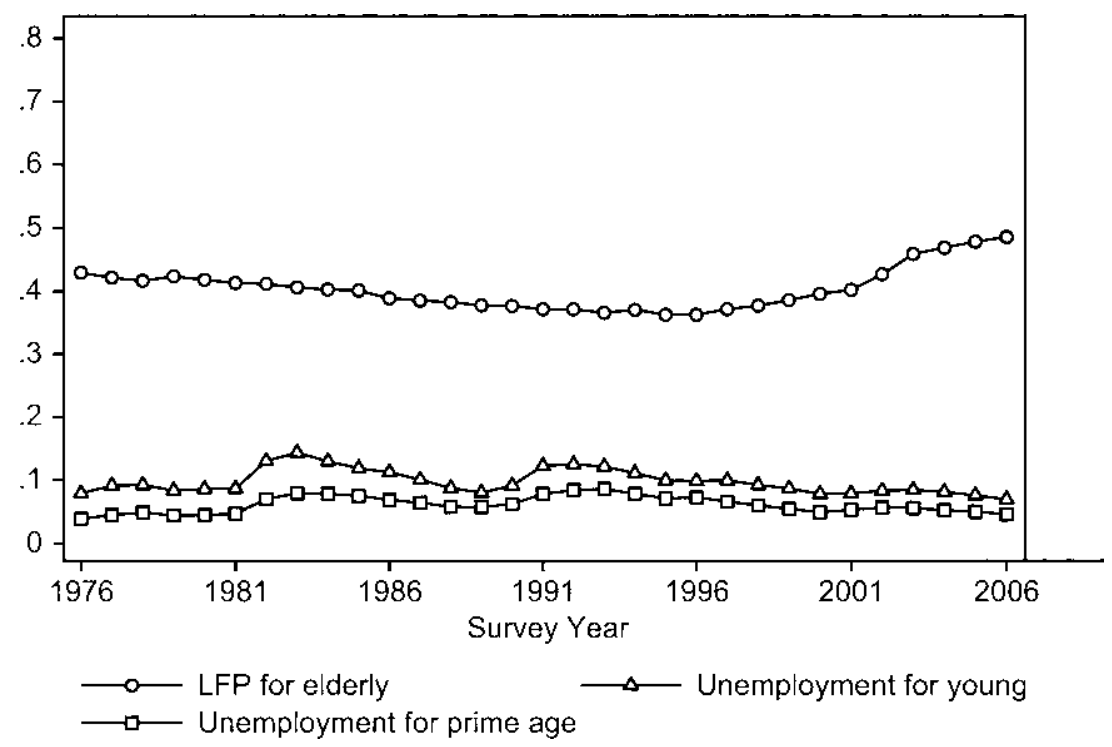

Fig. 2.4 Elderly labor force participation versus unemployment for the young and prime age, both sexes

young and prime aged dropped. Overall, this first look at the data gives no indication that trends in elderly LFP have any influence on the unemployment rates of the young and prime aged.

Figures 2.5 and 2.6 repeat the same analysis for males and females. As with figures 2.1 through 2.3 , male elderly employment shows a U-shaped pattern while for females a gentle upward trend becomes steeper in the mid1990s. The milder cyclicality of female youth unemployment compared to males carries forward to the prime-age females and males. However, for both males and females the prime age unemployment rates show less cyclicality than for the youth.

The next set of time series graphs show the LFP of the elderly against employment rates for the young and prime aged. This provides a slightly different view on the matter, since it is possible that elderly LFP does not affect unemployment if those displaced by elderly LFP move from employment to being out of the labor market entirely. Figure 2.7 shows both sexes together. Elderly LFP is repeated in figure 2.7 the same as was seen in figure 2.4. Employment rates for the young show strong business cycle effects, with drops in 1982 and in the early 1990s. Employment of the prime aged shows a similar pattern, but with muted amplitudes relative to the young. Again, in the post-1996 era the labor market of all three age groups is improving, with no sign of any crowding out of the employment of the young and prime aged from the increasing LFP of the elderly. Figures 2.8 and 2.9 repeat the 


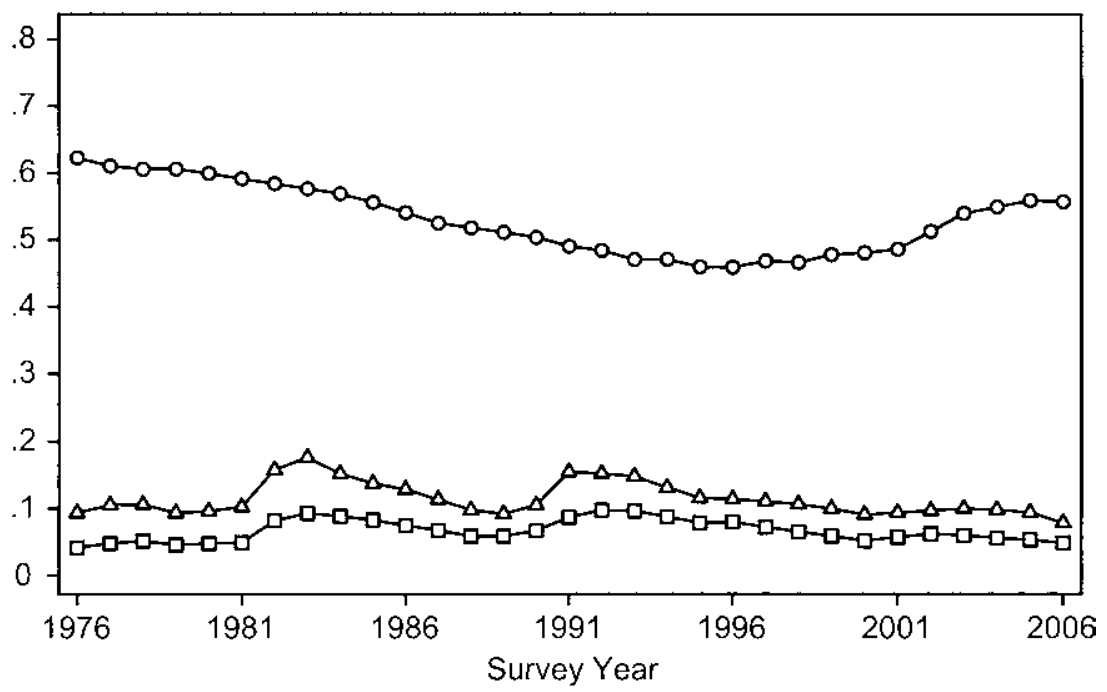

$\longrightarrow$ L_- LFP for elderly Unemployment for young $\longrightarrow$ U- Unemployment for prime age

Fig. 2.5 Elderly labor force participation versus unemployment for the young and prime age, males

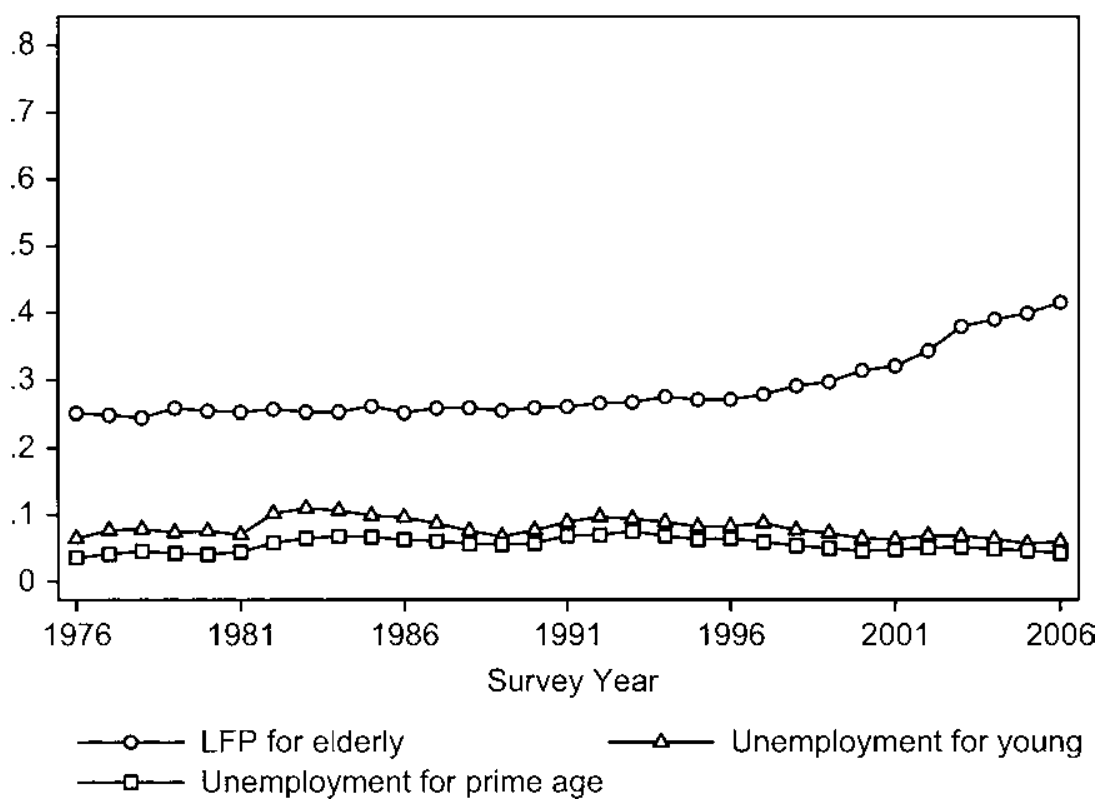

Fig. 2.6 Elderly labor force participation versus unemployment for the young and prime age, females 


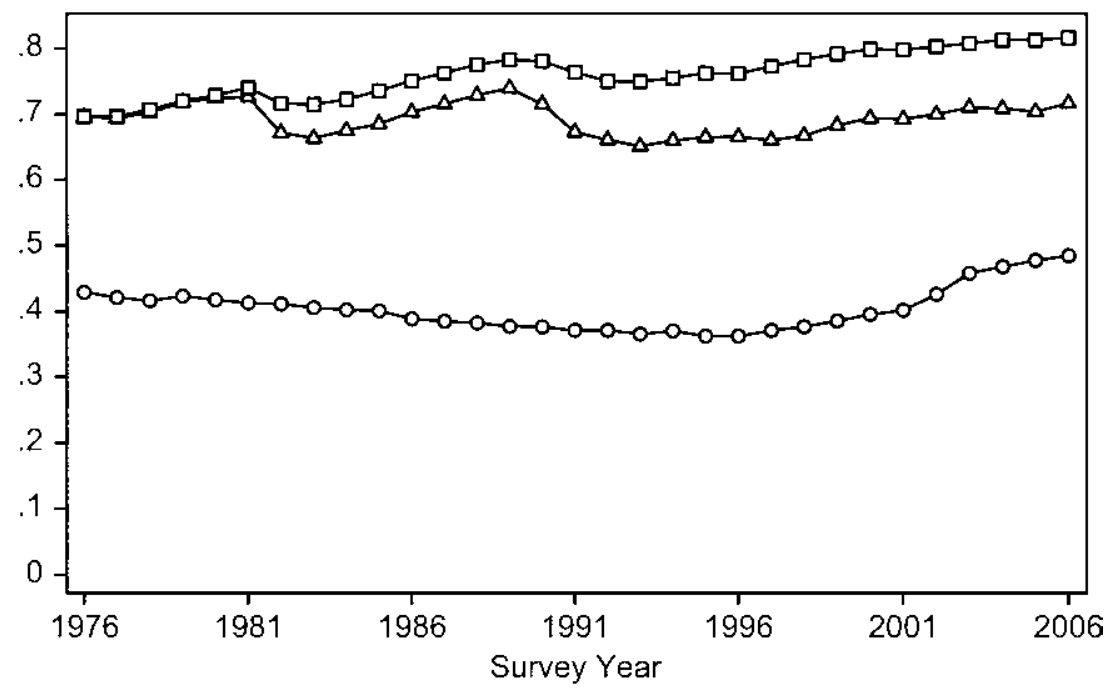

$\longrightarrow$ LFP for elderly $\longrightarrow$ Employment for prime age $\longrightarrow$ Employment for young

Fig. 2.7 Elderly labor force participation versus employment for the young and prime age, both sexes

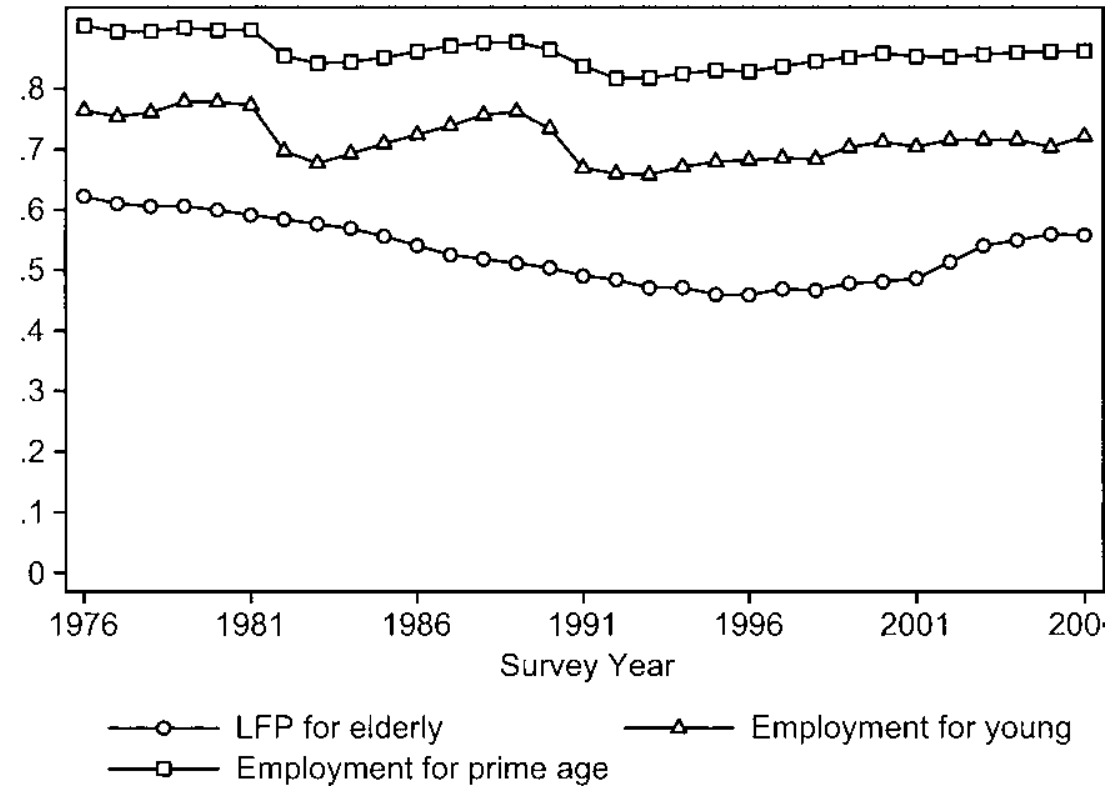

Fig. 2.8 Elderly labor force participation versus employment for the young and prime age, males 


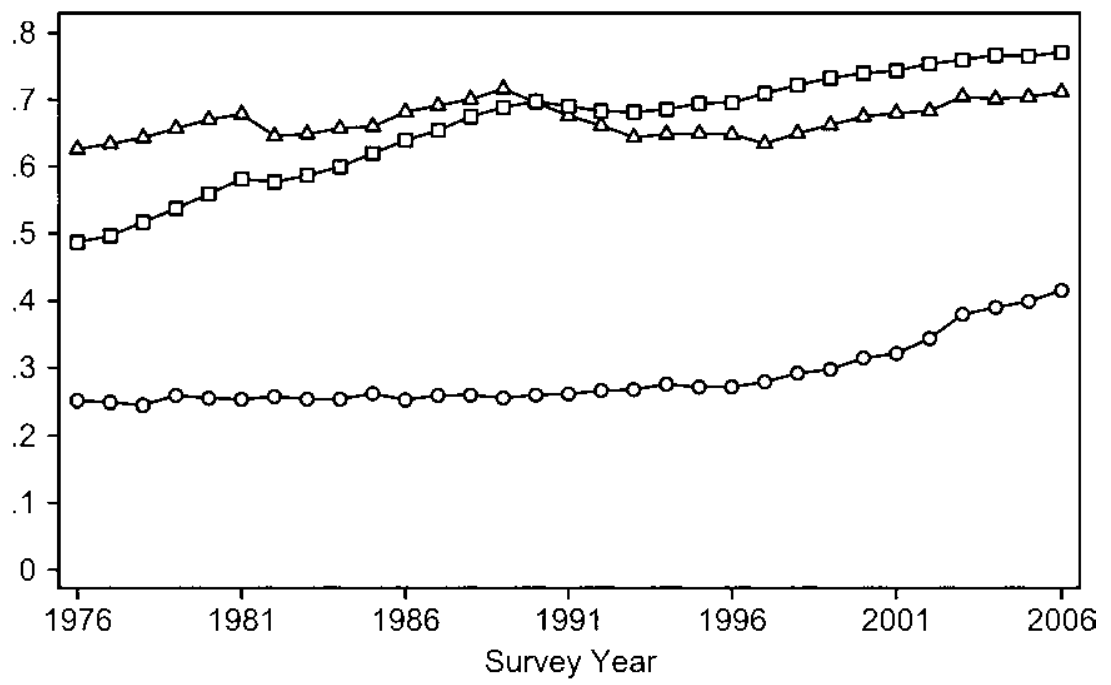

- LFP for eiderly
$\square-$ Employment for prime age

Fig. 2.9 Elderly labor force participation versus employment for the young and prime age, females

exercise for males and females separately. The previously noted trends are present here as well, with more cyclicality present for younger and male lines. The most striking trend is the sharp, consistent upward march of prime aged female employment over this time period. Overall, there does not appear to be much visual evidence of any crowding out of the employment of younger workers by the elderly.

\subsection{Regression Results}

In the next stage of our analysis, we turn to regression evidence to see if the inferences drawn from the graphs stand up to more rigorous tests. We estimate time series regressions of the form:

$$
Y_{t}=\beta_{0}+\beta_{1} \text { ELDERLYEMP }_{t}+X_{t} \beta_{2}+e_{t} .
$$

The dependent variable $Y_{t}$ is a measure of labor force participation, ELDERLYEMP $_{t}$ is the employment rate for the elderly age group, $X_{t}$ is a vector of national-level control variables, and $e_{t}$ is the usual error term. We use several different dependent variables, including the rate of unemployment, employment, and school attendance for the young, and unemployment and employment for the prime aged. The key independent variable in each regression is the rate of elderly employment. We try specifications with 
and without additional control variables. The additional control variables include the percent share of gross domestic product (GDP) in manufacturing, the level of GDP per capita, and the growth rate of GDP per capita.

We also try some transformations of the data. First, we try lagging the elderly employment variable by three years to see if there might be a delay in the timing of the response to changes in elderly employment. Second, we difference the data across five years in order to look at changes rather than levels. We chose five years in order to try to difference out fluctuations in the business cycle. Finally, we tried a five year difference of the log of elderly employment and the log of the dependent variables.

\subsubsection{Direct Effect of Elderly Employment on Young and Prime-Age Outcomes}

We first look for a direct effect of the employment of the elderly on younger labor market participants. The results appear in table 2.1. The result shown in the upper left cell reports that a one point increase in elderly employment predicts a -0.334 point drop in the unemployment rate for the young. This result is in the opposite direction of what would be expected if increased elderly employment cost younger participants work opportunities. The results for employment in the second column are consistent with the first column. Prime age results are also similar. These results in the top panel of the table, however, are from a specification without any control variables. In the bottom panel of the table we show that the coefficients are slightly attenuated when we control for manufacturing share, GDP, and GDP growth.

In the second row of the table, we use a three-year lag of elderly employment. The impact on young unemployment is now slightly positive, but not even close to statistically significant. The youth employment effect is still positive, however. Neither of the effects on prime aged behavior is statistically significant.

In the third and fourth rows of the table, we investigate differenced specifications. Using both the fifth difference and the fifth log difference, the inferences remain unchanged. There is no evidence of crowding out of labor market activity of the young when the elderly increase their labor force participation.

The bottom panel of table 2.1 repeats the same set of analyses, but includes several controls variables for GDP, GDP growth, and share of manufacturing in GDP. With the control variables included, the signs on almost all of the estimates are unchanged, but the magnitudes and statistical significance becomes more muted. This suggests that the results in the top half of the panel were driven in part by strong economic growth - in a strong growth environment both young and elderly employment improves.

Focusing on the prime aged results, some confusion arises. Elderly employment appears to have a negative impact on both unemployment and employ- 
Direct regressions of labor market crowd-out: Both sexes

\begin{tabular}{lcccccc}
\hline & \multicolumn{3}{c}{ Youth } & & \multicolumn{2}{c}{ Prime age } \\
\cline { 2 - 3 } & UE & EMP & SCH & & UE & EMP \\
\hline No controls & & & & & \\
$\quad$ Levels & -0.334 & 0.413 & -0.048 & -0.287 & 0.251 \\
& $(0.082)$ & $(0.107)$ & $(0.157)$ & & $(0.048)$ & $(0.188)$ \\
3-year lag on elderly & 0.031 & 0.371 & -0.571 & & -0.125 & -0.288 \\
$\quad$ employment & $(0.146)$ & $(0.175)$ & $(0.178)$ & & $(0.090)$ & $(0.225)$ \\
5-year difference & -0.347 & 0.638 & -0.275 & & -0.299 & 0.220 \\
& $(0.136)$ & $(0.175)$ & $(0.061)$ & & $(0.081)$ & $(0.117)$ \\
5-year log difference & -1.790 & 0.458 & -1.274 & & -2.445 & 0.139 \\
& $(0.604)$ & $(0.120)$ & $(0.238)$ & & $(0.594)$ & $(0.075)$ \\
With controls & & & & & \\
Levels & -0.224 & 0.407 & -0.349 & & -0.276 & -0.136 \\
& $(0.060)$ & $(0.103)$ & $(0.068)$ & & $(0.032)$ & $(0.049)$ \\
3-year lag on elderly & -0.149 & 0.558 & -0.539 & & -0.246 & -0.132 \\
$\quad$ employment & $(0.081)$ & $(0.141)$ & $(0.076)$ & & $(0.050)$ & $(0.061)$ \\
5-year difference & -0.187 & -0.078 & 0.001 & & -0.246 & -0.318 \\
& $(0.136)$ & $(0.131)$ & $(0.069)$ & & $(0.072)$ & $(0.081)$ \\
5-year log difference & -1.034 & 0.039 & -0.427 & -2.355 & -0.117 \\
& $(0.605)$ & $(0.069)$ & $(0.301)$ & $(0.585)$ & $(0.046)$ \\
\hline
\end{tabular}

Notes: Reported in each cell is the coefficient on elderly employment in separate regressions with the dependent variable listed in the column headings. The standard error is beneath each estimate in parentheses. The different specifications appear in each row of the table. The specifications are explained in the main text.

ment of prime aged men and women. This is not impossible, however, since employment and unemployment rates do not need to sum to one. Instead, being out of the labor force must rise. This provides some suggestive evidence of a degree of crowding out between elderly and prime aged individuals. We investigate this further following in our men-only sample.

We repeat the analysis in table 2.2 , but for males only. Through this time period, the graphical analysis tells us that there is more variation in unemployment and employment among males, and that male employment is higher. For this reason, we seek to find out if an analysis focused on males only reveals different results. The impact of elderly male employment rates on youth male unemployment rates is more muted than for the pooled sexes results, but still the signs are mostly negative. Similarly, the positive effect on youth employment persists in the male sample.

The prime aged results seen in the pooled men and women sample are strongly overturned here in the men-only sample. Again, the unemployment rate responds negatively to more elderly employment. However, in contrast to the pooled analysis, here with males only we find a positive response of prime aged employment to increasing elderly employment. This suggests that the negative relationship uncovered in table 2.1 might be driven by the 
Direct regressions of labor market crowd-out: Males only

\begin{tabular}{lcccccc}
\hline & \multicolumn{3}{c}{ Youth } & & \multicolumn{2}{c}{ Prime age } \\
\cline { 2 - 3 } & UE & EMP & SCH & & UE & EMP \\
\hline No controls & & & & & \\
Levels & -0.070 & 0.465 & -0.325 & & -0.152 & 0.352 \\
& $(0.075)$ & $(0.071)$ & $(0.044)$ & & $(0.042)$ & $(0.038)$ \\
3-year lag on elderly & 0.145 & 0.253 & -0.354 & & 0.010 & 0.178 \\
$\quad$ employment & $(0.074)$ & $(0.096)$ & $(0.027)$ & & $(0.049)$ & $(0.058)$ \\
5-year difference & -0.349 & 0.651 & -0.223 & & -0.308 & 0.451 \\
& $(0.148)$ & $(0.176)$ & $(0.051)$ & & $(0.084)$ & $(0.097)$ \\
5-year log difference & -1.791 & 0.553 & -1.246 & & -2.677 & 0.318 \\
& $(0.706)$ & $(0.148)$ & $(0.245)$ & & $(0.715)$ & $(0.069)$ \\
With controls & & & & & \\
Levels & -0.139 & 0.435 & -0.241 & & -0.190 & 0.335 \\
& $(0.051)$ & $(0.067)$ & $(0.037)$ & & $(0.026)$ & $(0.032)$ \\
3-year lag on elderly & -0.103 & 0.478 & -0.316 & & -0.170 & 0.347 \\
$\quad$ employment & $(0.063)$ & $(0.087)$ & $(0.033)$ & & $(0.037)$ & $(0.047)$ \\
5-year difference & -0.106 & 0.135 & -0.021 & & -0.169 & 0.180 \\
& $(0.141)$ & $(0.140)$ & $(0.052)$ & $(0.074)$ & $(0.077)$ \\
5-year log difference & -0.591 & 0.151 & -0.469 & & -2.010 & 0.183 \\
& $(0.766)$ & $(0.125)$ & $(0.263)$ & $(0.809)$ & $(0.061)$ \\
\hline
\end{tabular}

Notes: Reported in each cell is the coefficient on elderly employment in separate regressions with the dependent variable listed in the column headings. The standard error is beneath each estimate in parentheses. The different specifications appear in each row of the table. The specifications are explained in the main text.

secular and strong upward trend in female labor force participation seen in figure 2.9.

The largest impression from the evidence in table 2.1 and table 2.2 is the absence of any consistent indication that the labor market behavior of the elderly had a negative impact on the employment of the young. For the prime aged there was some evidence in favor of crowd-out in the pooled sample, but this was reversed in the men-only sample. What's more, if anything, the evidence suggests that employment of the different age groups tends to move together rather than in opposite directions.

\subsubsection{Effect of Retirement Incentives on Employment Patterns}

A concern with the evidence presented in tables 2.1 and 2.2 is that both elderly employment and young employment are driven by common but unmeasured factors. To try to improve the inferences on the causal nature of the relationship, we turn to an approach that exploits changes in policy through time. We develop an annual index of the incentives for elderly workers to retire, based on the parameters of Canada's public pension system. When the incentive index is larger, there is a greater incentive to exit the 


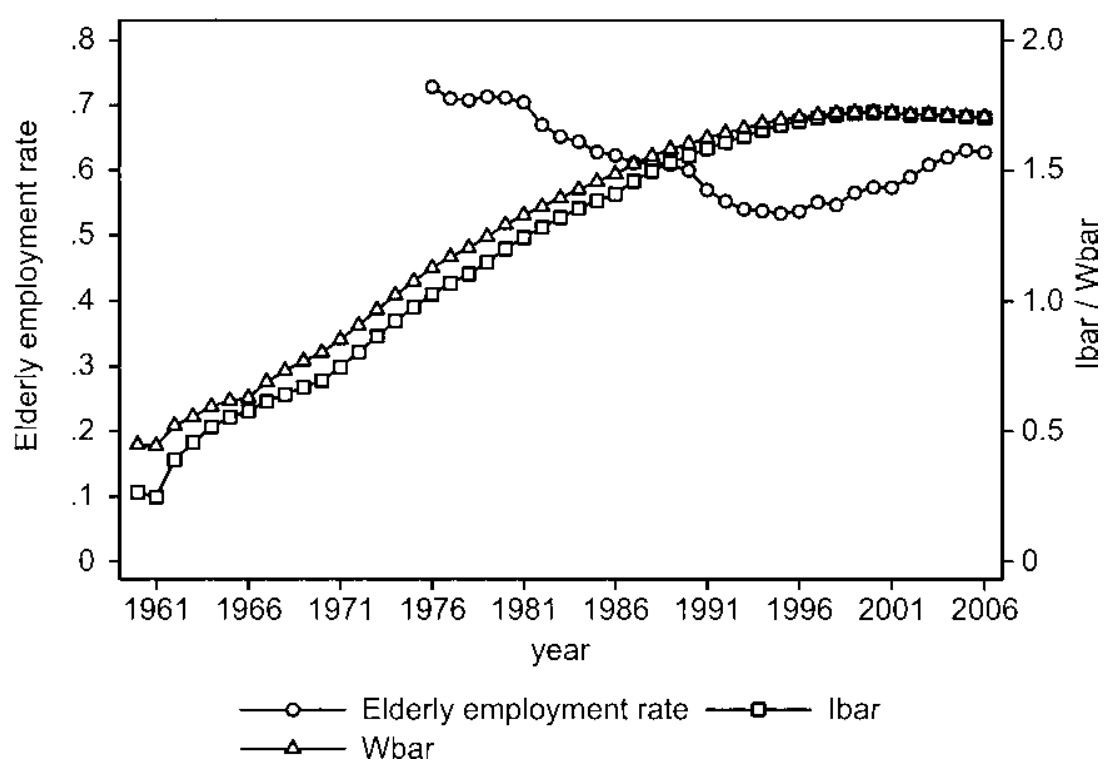

Fig. 2.10 Elderly employment rate, $\bar{I}(y)$ and $\bar{W}(y)$

labor market. We provide further detail on the construction of this index in the appendix.

We graph the incentive measures in figure 2.10. There are two indexes we use: Wbar and Ibar. Both are described in detail in the appendix. The Wbar represents the average Income Security Wealth among labor market participants. The Wbar includes both Income Security Wealth and a dynamic incentive measure called "peak value" that captures the pension accrual from continued work. For the case of Canada, the difference between current and peak wealth is typically quite flat, so there is little difference between Ibar and Wbar. Both of these incentive measures show strong, consistent growth until the mid1990s when they level out. The figure also graphs the employment rate among the elderly. It is only available from 1976 when the LFS data start. Elderly employment declines through the mid-1990s when it begins to rebound.

This graph suggests there may be a relationship between incentives and employment of the elderly. However, given that we have only two time series to conduct the inference, it is far from certain that the relationship observed is causal. Other factors could be influencing each of these trends.

Another view on this relationship is provided in figure 2.11, which plots the fifth difference of the Ibar measure and elderly employment. There appears to be a tight negative relationship between them. However, upon closer inspection, the serial pattern of the data points cautions us to consider that this relationship may be spurious. 


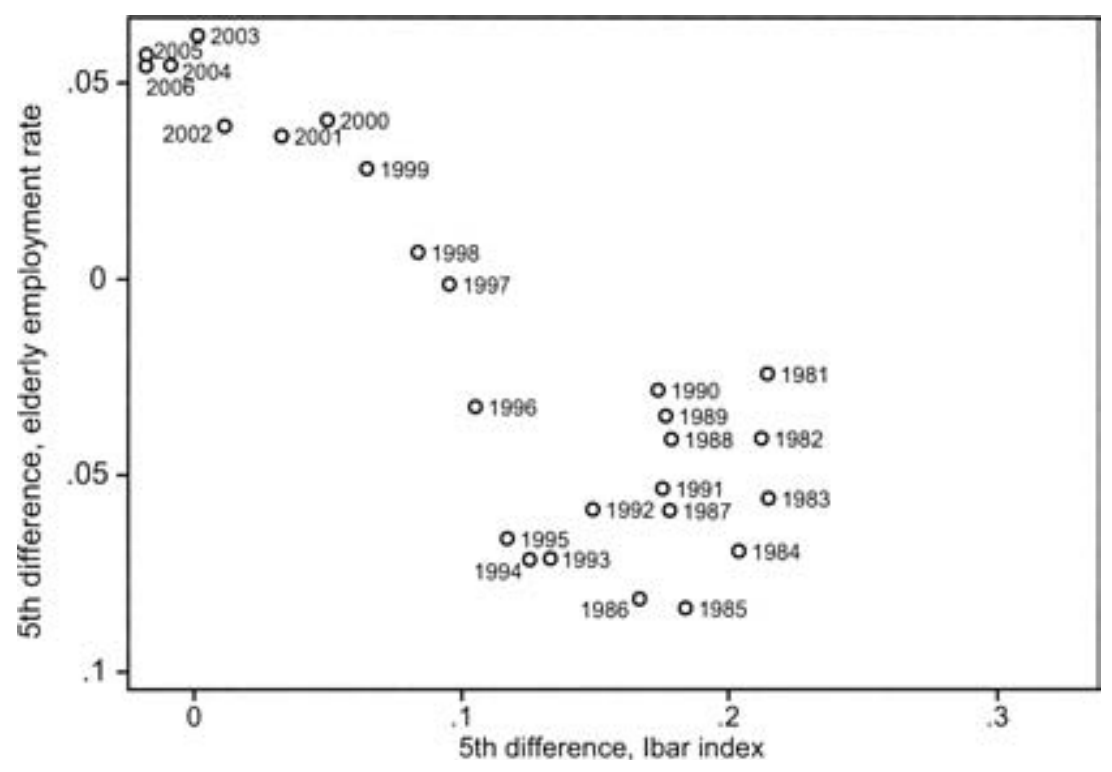

Fig. 2.11 Elderly employment rate and $\bar{I}(y)$ index in fifth differences

The regression results are displayed in table 2.3 for both sexes pooled together. To begin, we look at the results for the elderly. These results are in some sense the "first stage," as we expect the incentives to have an impact on the work behavior of the elderly as a precursor to their impact on the younger workers. The results without control variables in the top half of table 2.3 are mixed. However, when the control variables are included in the bottom half of the table, the results become more consistent. As the policy incentives to retire increase, the employment of the elderly decreases. There is also a small increase in the measured unemployment rate of the elderly. These results hold across all four specifications in the table.

When looking at the results for the young and the prime aged, the specification can be thought of as a "reduced form" estimate. That is, we are estimating the effect of a higher incentive for the elderly to retire on the work behavior of the young and middle aged. The presumed path through which the changes in incentives affect the younger workers is through their impact on the labor market behavior of the elderly. For the young, the results for employment are in some places small and insignificant but are almost all negative. This suggests that, if anything, a decrease in elderly employment is associated with a decrease in young employment. This does not support the crowd-out story. The results for the prime aged individuals, however, are more mixed. The positive coefficients on employment suggest that greater incentives for the elderly to retire are associated with more work by middleaged workers, which is consistent with the idea that induced retirement of the 


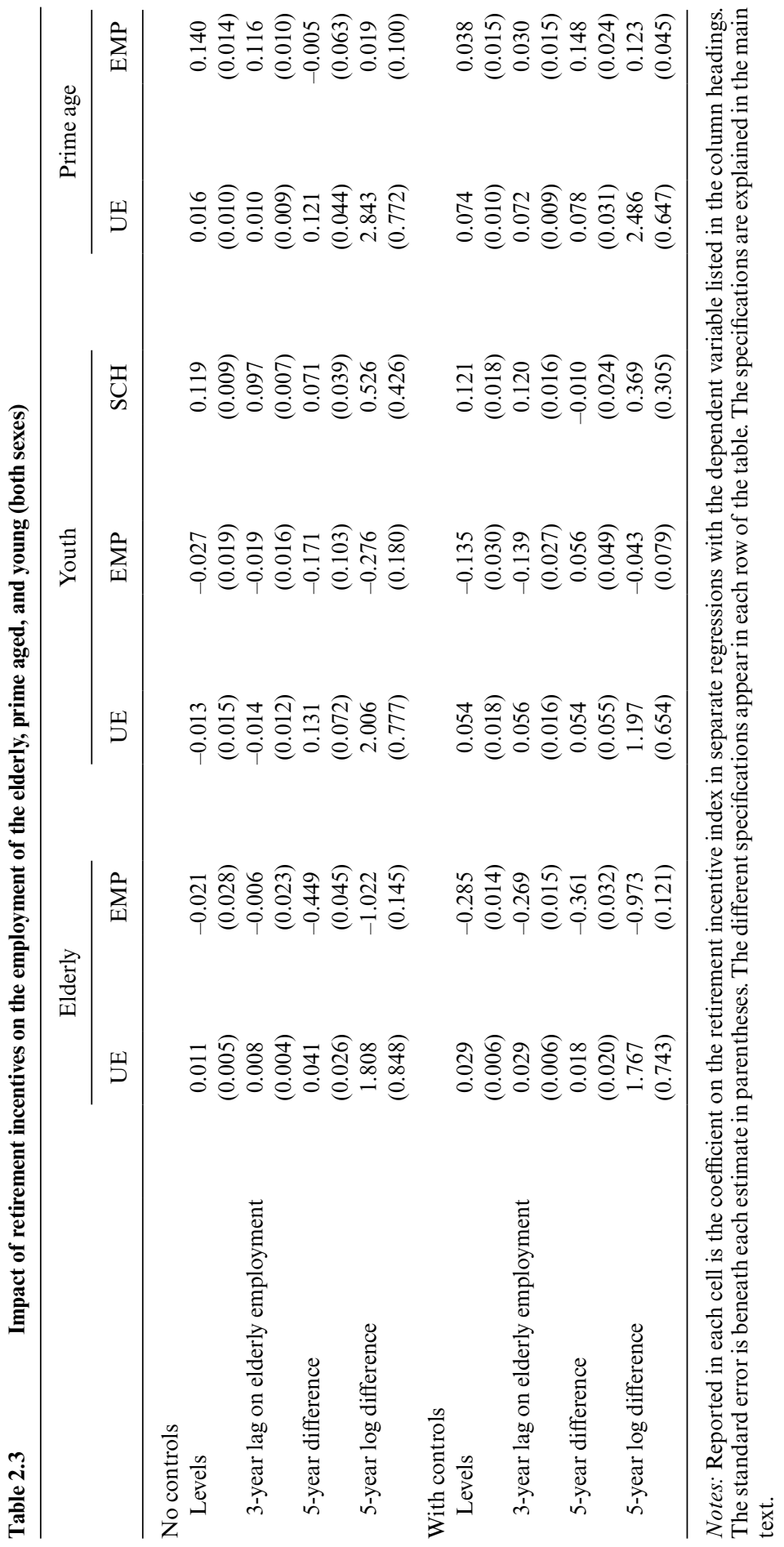


elderly creates more employment for the middle aged. However, the unemployment results for the prime aged are also positive, which is contradictory to the employment results. This leads us again to look at males only.

In table 2.4 we explore the results in the subsample of males. To begin, the "first-stage" effect of the incentive measure on elderly employment is very strong here. For example, in the levels regression with controls, the coefficient in table 2.4 is -0.443 , versus -0.285 with both sexes pooled in table 2.3 . The estimates for youth unemployment and employment are for the most part consistent in both magnitude and sign with the estimates from table 2.3. For the prime aged males, however, we now find a negative relationship for employment. That is, we no longer have evidence of crowd-out. As with the previous analysis in tables 2.1 and 2.2, this difference may be driven by a secular upward trend in female employment as seen in figure 2.9.

In sum, the results using the incentive to retire index suggest that the incentives may have an impact on the elderly, but it is not clear if it is causal. The changes in elderly employment have a mixed and mostly small impact on the working behavior of the young and prime aged. There is some evidence in favor of a positive relationship between elderly and the employment of younger individuals, but no consistent evidence of any crowding out.

\subsection{Conclusions}

In this chapter we have studied the relationship between the work of the elderly and the work of Canadians in other age groups. Historically, the political concern about the impact of elderly employment on younger workers seems to be strongly related to the business cycle and especially the unemployment rates of younger workers. In the graphs, we find little visual evidence that trends in elderly labor force participation have had an impact on the labor markets of the younger. Finally, our regression evidence has shown that - if anything - the employment of the young and prime aged tends to move in the same direction as the elderly.

Several important caveats limit the conclusions that may be drawn from our results. First, the movements in elderly labor force participation over the 1976 to 2006 period have not been sharp, so there simply may not be enough variation to identify any effects on other labor markets. Second, the results we find here for Canada may not hold in other countries with different labor market institutions, practices, and histories. Finally, the time series regressions we run are in some ways quite crude and rely on very few observations to describe the behavior of millions of workers. With these caveats in mind, however, it is possible for us to conclude that we find no strong evidence of elderly employment crowding out the work of the young. 


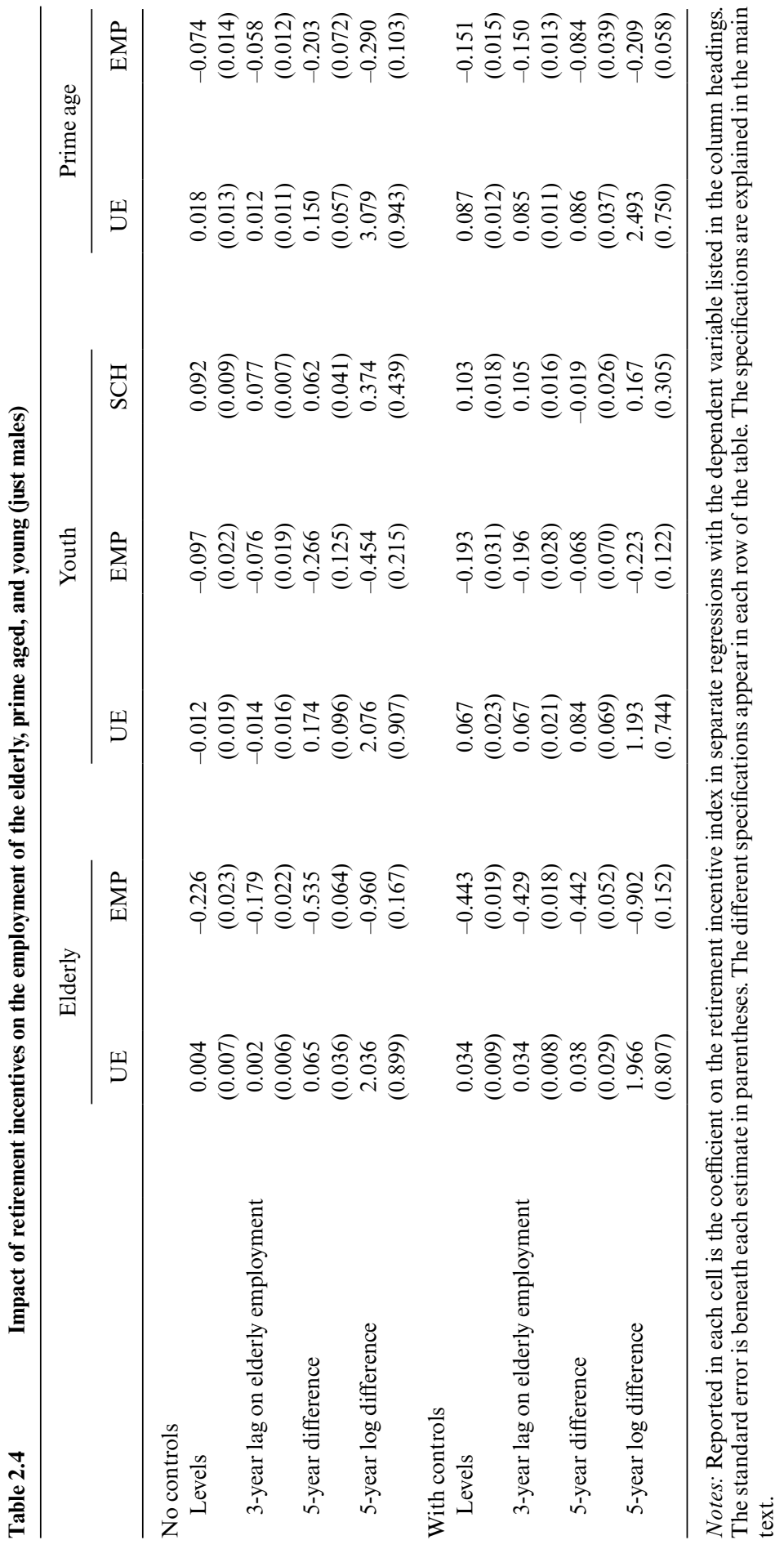




\section{Appendix}

\section{Calculating the Incentive Measure}

The goal of the exercise is to arrive at a single incentive number for each calendar year to be used in the time series regressions. We begin with a single birth cohort born in 1920 and build a lifetime earnings profile for them. Data are drawn from the Survey of Consumer Finances for available years and then extrapolated forward and backward using indexes of wage growth. This earnings profile is then shifted for inflation forward and backward to generate equivalent real wage profiles for all birth cohorts. We repeat this exercise for each decile of the earnings distribution, separately for males and females. This method ensures that the only difference in incentive measures across years will be in changes in benefit formulas and not cross-cohort differences in wages.

These cohort age-earnings profiles are next pushed through our Canadian income security benefits calculator developed in Baker, Gruber, and Milligan (2004, 2007). At each age from fifty-five to sixty-nine, we calculate the capitalized value of future benefits (Income Security Wealth or ISW) and also the "peak value" concept found in Baker, Gruber, and Milligan (2004). The peak value represents the difference between current ISW and its highest value in the future, given current information for a forward-looking individual.

To collapse this down to an annual time series, we start by recognizing that an individual viewed at age $a$ has faced retirement incentives at age $a, a-1$, $a-2, \ldots$ back to the first age of eligibility. We therefore average the incentives within a cohort across ages (from the current age back to age fifty-five), using the aggregate age-year-sex-specific labor force participation as weights. We generate the age-year-sex labor force participation rates from the Survey of Consumer Finances. Since this survey only goes back to 1971 and is also missing some years, we fill in missing years and extrapolate backwards using an assumption of constant age-sex labor force participation rates. This calculation gives us an average exposure to retirement incentives for each cohort in each year of interest.

The final step involves collapsing the average incentive measures to a single number for each year. This means we must average the incentive measures faced by each cohort in a given year. To do this, we weight by the proportion of the population represented by each age in a given year.

To enrich the measurement of incentives, we assign a weight to the ISW component and the peak value component. We determined these weights using an iterative technique, finding weights that maximized the fit of a regression of elderly LFP on the incentive measure.

The foregoing can be expressed mathematically as follows. The incentive measure $I$ at age $a$ and year $y$ can be expressed as: 


$$
I(a, y)=\{\gamma W(a, y)+\alpha[W(a, y)-P V \times(a, y)]\},
$$

where $W(a, y)$ is the ISW at age $a$ and year $y, P V \times(a, y)$ is the peak value of ISW, and $\alpha$ and $\gamma$ are the weighting parameters for the wealth level and peak value difference, respectively. These $I(a, y)$ terms are then summed across all previous ages, within cohort:

$$
\bar{I}(a, y)=\sum_{a=55}^{a=69}\left(\left\{P(a, y) \times\left[\frac{\sum_{t=0}^{a-55} I(a, y) \times \operatorname{LFP}(a-t, y-t-1)}{\sum_{t=0}^{a-55} \operatorname{LFP}(a-t, y-t-1)}\right]\right\} / \sum_{a=55}^{a=69} P(a, y)\right),
$$

where $\operatorname{LFP}(a-t, y-t-1)$ is the labor force participation rate for a member of the cohort in a previous year. The extra minus one accounts for the fact that we want the labor force participation rate at the beginning of the year, not during the year. Finally, we average across all cohorts in a particular year, where $P(a, y)$ is the population of the cohort in a given year. This $\bar{I}(y)$ term is the incentives index used for the regressions appearing in tables 2.3 and 2.4.

We also make use of $\bar{W}(y)$, which is calculated by substituting the ISW of the individual at age $a$ and year $y, W(a, y)$, in for $I(a, y)$. This $\bar{W}(y)$ term calculates the average pension wealth across individuals in a given year.

\section{References}

Baker, M., J. Gruber, and K. Milligan. 2004. Income security programs and retirement in Canada. In Social security programs and retirement around the world: Micro-estimation, ed. J. Gruber and D. A. Wise, 99-152. Chicago: University of Chicago Press.

. 2007. Simulating the response to reforms of Canada's income security programs. In Social Security programs and retirement around the world: Fiscal implications of reform, ed. J. Gruber and D. A. Wise, 83-118. Chicago: University of Chicago Press.

Gruber, J. 1999. Social Security and retirement in Canada. In Social Security Programs and retirement around the world, ed. J. Gruber and D. A. Wise, 73-100. Chicago: University of Chicago Press.

Milligan, K. 2005. Making it pay to work: Improving the incentives in Canada's public pension system. Commentary 218. C. D. Howe Institute: Toronto, Ontario.

Schirle, T. 2008. Why have the labor force participation rates of older men increased since the mid-1990s? Journal of Labor Economics 26 (4): 549-94. 